\title{
QUALIDADE PÓS-COLHEITA DE CULTIVARES DE BANANEIRA DO GRUPO 'MAÇÃ', NA REGIÃO DE BELÉM - PA ${ }^{1}$
}

\author{
ANA VÂNIA CARVALHO ${ }^{2}$, LARA LIMA SECCADIO ${ }^{3}$, MOISÉS MOURÃO JÚNIOR ${ }^{4}$, \\ WALNICE MARIA OLIVEIRA DO NASCIMENTO²
}

RESUMO-O presente trabalho teve por objetivo realizar a caracterização física e físico-química de três cultivares de bananeira do subgrupo 'Maçã', em diferentes estádios de maturação, bem como a avaliação sensorial dos frutos maduros. Os cachos de banana das cultivares Caipira, Thap Maeo e BRS Tropical foram colhidos no estádio 2 de coloração da casca (verde-maduro) e armazenados sob condição ambiente, sendo avaliados com relação ao comprimento e diâmetro dos frutos, firmeza, $\mathrm{pH}$, sólidos solúveis, acidez titulável, açúcares redutores, não redutores e totais da polpa neste mesmo estádio, e à medida que atingiam os graus 3; 5 e 7 de coloração da casca. Os frutos completamente maduros foram ainda analisados quanto à aceitação sensorial, por meio dos atributos aroma, cor da polpa, textura e sabor dos frutos. Durante o período de maturação das bananas, observaram-se, para todas as cultivares avaliadas, aumento da acidez, sólidos solúveis e açúcares, fatores responsáveis pelo aroma e sabor da fruta. Verificou-se também redução na firmeza dos frutos com o amadurecimento e redução do $\mathrm{pH}$ para as cultivares estudadas. Com relação à análise sensorial, destacaram-se as cultivares Tropical e Thap Maeo, com as maiores notas médias para todos os atributos sensoriais analisados.

Termos para indexação: Musa spp; estádio de maturação; caracterização físico-química, análise sensorial.

\section{POSTHARVEST QUALITY OF 'MAÇA' BANANA CULTIVARS IN BELÉM REGION- PA}

\begin{abstract}
The present study aimed to characterize the physical and physical-chemical properties and perform sensory evaluation of ripe fruits of three banana cultivars of the subgroup 'Maçã ' at different stages of maturation. Bunches of Caipira, Thap Maeo, and BRS Tropical cultivars were harvested at stage 2 of color peel (green-mature) and stored at room temperature. They were evaluated at color peel stages 2, 3, 5, 7 with respect to length and diameter of the fruits. The following properties of the pulp were investigated: firmness, $\mathrm{pH}$, soluble solids, titratable acidity and sugar concentration (reduced, not reduced and total). Fully ripe fruits were also analyzed regarding the sensory acceptance through the attributes aroma, pulp color, texture, and flavor of fruit. As the ripening progressed, acidity, soluble solids and sugars increased, factors responsible for the fruit flavor, as well as the decrease in fruit firmness and the $\mathrm{pH}$ reduction were observed for all cultivars. With respect to sensory analysis, the Tropical and Thap Maeo cultivars presented the highest average scores for all sensory attributes evaluated.
\end{abstract}

Index terms: Musa spp.; maturity; physical-chemical characterization; sensory analysis.

\footnotetext{
${ }^{1}$ (Trabalho 077-11). Recebido em: 08-02-2011. Aceito para publicação em: 10-08-2011.

${ }^{2}$ Pesquisador da Embrapa Amazônia Oriental, doutor, Av. Dr. Enéas Pinheiro, s/n - Marco. CEP: 66095-100, Belém-PA. E-mails: anavania@cpatu.embrapa.br; walnice@cpatu.embrapa.br

${ }^{3}$ Aluna do curso de Engenharia de Alimentos da Universidade Federal do Pará, Rua Augusto Correa, 01 - Guamá. CEP: 66075-110, Belém-PA. E-mail: laraseccadio@hotmail.com

${ }^{4}$ Pesquisador, mestre, Embrapa Amazônia Oriental, Av. Dr. Enéas Pinheiro, s/n - Marco. CEP: 66095-100, Belém-PA. E-mail: mmourao@cpatu.embrapa.br
} 


\section{INTRODUÇÃO}

A banana (Musa spp.) é uma fruta originária do sudeste asiático e existem indícios do seu cultivo desde 5000 a.C. ou até mesmo 8000 a.C. Atualmente, está distribuída em várias regiões tropicais, constituindo uma das frutas mais consumidas no mundo. Possui grande importância econômica nos países tropicais além de ser muito apreciada pelo sabor, facilidade de consumo, baixo custo e também por ser fonte de energia, vitaminas e minerais (CEAGESP, 2010; SILVA et al., 2006). No Brasil, é cultivada em praticamente todos os estados, sendo a segunda fruta mais consumida no País, a maior parte in natura (CEAGESP, 2010; IBRAF, 2007; MATTOS et al., 2010).

Durante o amadurecimento da banana, ocorrem transformações na aparência, textura e composição química, a qual é caracterizada pela conversão de amido em açúcares, com consequente incremento nos sólidos solúveis, açúcares, bem como elevação da acidez, marcada pela redução do $\mathrm{pH}$ e concomitante aumento da acidez titulável. O amaciamento dos frutos consiste numa das mais flagrantes modificações observadas ao longo do amadurecimento, sendo associado à hidrólise de amido e solubilização das substâncias pécticas. Paralelamente, na casca, observam-se o amarelecimento originado da degradação da clorofila e o aparecimento dos pigmentos carotenoides, responsáveis pela coloração amarela (MEDINA; PEREIRA, 2010; VILAS BOAS et al., 2003).

Apesar do grande número de variedades de banana, quando se consideram aspectos como produtividade, tolerância a pragas e doenças, resistência à seca, porte e resistência ao frio, restam poucas cultivares com potencial agronômico para serem utilizadas comercialmente. Dentre as cultivares mais difundidas no Brasil, a banana 'Maçã', pertencente ao grupo 'Maçã', apresenta ótima qualidade e excelente aceitação no mercado consumidor devido ao seu sabor mais delicado, obtendo-se maiores preços no mercado (AGUIAR, 2006; CEAGESP, 2010; SILVA et al., 2002). Porém, essa cultivar apresenta alta suscetibilidade a uma doença fúngica denominada Maldo-Panamá, que impossibilita o cultivo da banana 'Maçã' por vários ciclos e está dizimando-a de norte a sul do País (LEONEL; DAMATTO JÚNIOR, 2007).

Uma das estratégias de solução para se obterem frutos mais resistentes contra doenças e pragas é a criação de novas cultivares mediante o melhoramento genético, o que possibilita a obtenção de híbridos superiores (SILVA et al., 2002). Programas de melhoramento genético de bananeira têm atentado para os problemas de cultivo da planta, buscando a descoberta de cultivares que apresentem, principalmente, alta produtividade e resistência a doenças e pragas. A substituição de uma cultivar de bananeira tradicionalmente explorada em uma ou várias regiões do mundo é tarefa difícil, pois a banana é uma fruta cujos consumidores são muito exigentes em sabor, fato que determina sua aceitação no mercado e o sucesso em termos de adoção pelos bananicultores (MATSUURA et al., 2004; PEREIRA et al.,2002).

Portanto, mesmo quando se pensa em frutos mais resistentes às doenças, atributos de qualidade como aparência, sabor, aroma, textura, vida útil, entre outros, não podem ser esquecidos, pois são características fundamentais para o consumidor e afetam diretamente sua compra (MATSUURA et al., 2004).

O presente trabalho teve como objetivo a caracterização física e físico-química de três cultivares de bananeira do subgrupo 'Maçã', em diferentes estádios de maturação, bem como a avaliação sensorial dos frutos maduros.

\section{MATERIAL E MÉTODOS}

Os cachos de banana das cultivares Caipira, Thap Maeo e BRS Tropical, pertencentes ao subgrupo 'Maçã', foram colhidos em área de cultivo experimental da Embrapa Amazônia Oriental, em Belém-PA, no estádio 2 (E2) de coloração da casca (verde-maduro). Após a colheita, os cachos foram transportados para o laboratório e armazenados sob condição ambiente $\left(28 \pm 3^{\circ} \mathrm{C}\right.$ e $74,5 \pm 16,5 \%$ UR), em delineamento inteiramente casualizado, com três tratamentos (cultivares), três repetições e parcela constituída de um cacho. Os cachos foram avaliados à medida que atingiam os graus 3;5 e 7 de coloração da casca dos frutos, sendo o grau 3 (E3) definido como frutos com coloração da casca $50 \%$ verde e $50 \%$ amarela; grau 5 (E5) frutos com coloração amarela e extremidades ainda verdes; grau 7 (E7) frutos completamente amarelos com manchas marrons (PINHEIRO et al., 2005).

Para a caracterização dos frutos, foram realizadas as seguintes análises: comprimento e diâmetro dos frutos da segunda penca (utilizando paquímetro metálico Vonder, sendo avaliados todos os frutos da segunda penca de cada cacho), firmeza da polpa (medida em 10 frutos/cacho após a retirada da casca dos frutos, com penetrômetro modelo PFT-327, sendo realizadas duas medições por fruto e os resultados expressos em Newton), pH (ASSOCIATION OF OFFICIAL ANALYTICAL CHEMISTS, 1997), sólidos solúveis (AOAC, 1997), acidez titulável (AOAC, 1997) e açúcares redutores, não redutores e 
totais (por titulação de oxirredução, segundo método do INSTITUTO ADOLFO LUTZ, 1985). Para todas as análises, foram avaliados os frutos, da segunda penca de três cachos em cada estádio de maturação, sendo que cada cacho representou uma repetição. Para a análise das dimensões comprimento e diâmetro dos frutos, foi calculado o valor médio de cada cultivar considerando-se todos os estádios de maturação.

Os dados provenientes da caracterização físico-química foram analisados por meio do modelo linear geral (GLM), via análise de variância, medidas repetidas no tempo (Repeated Measures ANOVA). Dada a significância do modelo, os valores médios foram ordenados segundo o teste de comparação múltipla de Tukey. Tanto na análise de variância, quanto no texto de comparação múltipla, foi adotado o nível de significância de 5\%. As análise foram conduzidas com auxílio da planilha Excel e dos softwares SISVAR e SigmaPlot 11.0.

Estudos sensoriais foram realizados para determinar a aceitação das três cultivares de bananeira do grupo 'Maçã' pelos consumidores. A avaliação sensorial foi realizada por 60 provadores não treinados, entre funcionários, visitantes e estagiários da Embrapa Amazônia Oriental. Empregou-se o teste de aceitação com escala hedônica estruturada de 9 pontos $(9=$ gostei muitíssimo; $8=$ gostei muito; $7=$ gostei moderadamente; $6=$ gostei ligeiramente; $5=$ nem gostei nem desgostei; 4 = desgostei ligeiramente; 3 = desgostei moderadamente; 2 = desgostei muito; $1=$ desgostei muitíssimo) (STONE; SIDEL, 1993). As amostras foram apresentadas aos consumidores à temperatura ambiente, em pratos plásticos descartáveis codificados com números aleatórios de três dígitos e avaliadas quanto ao aroma, cor da polpa, sabor e textura.

Os resultados das características sensoriais avaliadas foram submetidos à análise de variância, e as médias, quando significativas, comparadas pelo teste de Tukey, a 5\% de significância, com auxílio do programa SAS 8.0 (Statistical Analysis System).

\section{RESULTADOS E DISCUSSÃO}

Na Figura 1, estão apresentadas as médias do comprimento e diâmetro dos frutos das cultivares de banana analisadas. Nota-se que a cultivar Caipira obteve comprimento superior, $11,19 \mathrm{~cm}$, em relação às cultivares Thap Maeo (10,44 cm) e Tropical (10,55 $\mathrm{cm})$, porém essa diferença não foi estatisticamente significativa. No entanto, para o diâmetro, verifica-se que os frutos da cultivar Thap Maeo apresentaram valor médio estatisticamente superior, de $38,92 \mathrm{~mm}$, em relação às demais cultivares, que apresentaram valores médios de $35,54 \mathrm{~mm}$ e $34,20 \mathrm{~mm}$ para as cultivares Caipira e Tropical, respectivamente. Segundo Matsuura et al. (2004), o diâmetro é a segunda característica de maior importância, em relação à aparência do fruto. Os autores, em estudo sobre preferências do consumidor quanto aos atributos de qualidade dos frutos de banana, relatam um tamanho médio de 26 a $35 \mathrm{~mm}$ para essa característica, valores próximos aos relatados no presente trabalho.

De acordo com as normas de classificação sugeridas pelo Programa Brasileiro para a Modernização da Horticultura (PBMH; PIF, 2006), o agrupamento em classes garante a homogeneidade de tamanho entre frutos do mesmo lote e é determinada pelo comprimento do fruto. Já as categorias descrevem a qualidade de um lote de banana, através da diferença de tolerância aos defeitos graves e leves em cada uma delas. Para cada categoria, de acordo com o grupo, há um diâmetro (calibre) mínimo exigido por fruto, sendo que, para o grupo Maçã, os frutos pertencem à Classe 9 , por apresentarem comprimentos entre 9 e $12 \mathrm{~cm}$, caso das três cultivares analisadas no presente estudo. Já com relação ao diâmetro, as cultivares analisadas apresentaram diâmetros médios que variaram entre 34,20 a 38,92 $\mathrm{mm}$, sendo classificadas na Categoria Extra, em que o diâmetro mínimo dos frutos deve ser de $32 \mathrm{~mm}$.

Na Tabela 1, é apresentada a caracterização físico-química das cultivares de banana do grupo 'Maçã' avaliadas nos diferentes estádios de maturação dos frutos.

Com relação à firmeza da polpa, inicialmente, os frutos apresentaram valores de 39,98; 38,27 e $52,02 \mathrm{~N}$, para as cultivares Caipira, Thap Maeo e Tropical, respectivamente. Com a evolução dos estádios de maturação, pôde-se observar um decréscimo na firmeza, passando de 43,42 N no estádio E2 para $5,39 \mathrm{~N}$ no $\mathrm{E} 7$, não sendo verificadas, para os frutos completamente maduros, diferenças significativas entre as cultivares estudadas. A redução na firmeza da polpa dos frutos geralmente ocorre devido à ação de enzimas que atuam em sua parede celular. Segundo Vilas Boas et al. (2003) e Silva et al. (2006), o amaciamento dos frutos está associado à hidrólise de amido e à solubilização das substâncias pécticas, e também à perda de água. Para as cultivares estudadas, observou-se o maior valor médio de firmeza para a cv. Tropical. Já para as cvs. Thap Maeo e Caipira, não foram observadas diferenças em termos globais, para essa característica.

Na Tabela 1, pode-se constatar que o $\mathrm{pH}$ reduziu, à medida que avançou a maturação dos frutos, para todas as cultivares analisadas, porém com tendência a aumento dos valores para as culti- 
vares Caipira e Tropical, no estádio 7 de maturação dos frutos. Os valores médios de $\mathrm{pH}$ variaram de 5,44 (E2) a 4,55 (E7). Esses resultados obtidos foram corroborados por Lucena et al. (2004), que observaram redução no $\mathrm{pH}$ em função do grau de maturação de bananas da variedade prata-anã. Segundo Álvares (2003), os valores de pH diminuem após a colheita da banana, porém podem aumentar no final do amadurecimento ou início da senescência das frutas, tendência observada neste trabalho. As médias de $\mathrm{pH}$ encontradas para os frutos no estádio 2, para todas as cultivares, estão dentro da faixa indicada por Bleinroth (1995), que considera aceitável a variação de 5,0 a 5,6 para frutos verdes. Já para os frutos maduros (E7), observou-se $\mathrm{pH}$ entre 4,18 a 4,93 , valores próximos aos relatados por Matsuura et al. (2002) e Jesus et al. (2004), que encontraram valores variando de 4,3 a 4,85 para diferentes genótipos e híbridos de bananeira.

A acidez titulável média nos frutos de bananeira do grupo 'Maçã' analisados atingiu valor global mínimo de $0,13 \%$ (E2) e máximo de $0,35 \%$ (E5). Para todas as cultivares, pôde-se constatar, de forma significativa, um aumento no teor de acidez do estádio 2 para o estádio 7, que, de acordo com Chitarra e Chitarra (2005), pode estar relacionado ao desdobramento do amido em açúcares redutores, e sua conversão em ácido pirúvico, provocada pela respiração das frutas. Para a cultivar Thap Maeo, observaram-se os maiores valores de acidez titulável, ao longo de todo o período de maturação, quando comparado aos valores obtidos para as demais cultivares. Esse fato coincide, como esperado, com os menores valores de $\mathrm{pH}$ observados para essa cultivar (Tabela 1), ao longo da maturação dos frutos. Alencar et at. (2010) verificaram que, ao contrário do que ocorre com a maioria das frutas, a acidez aumenta durante a maturação da banana, concordando com Matsuura et al. (2001), que observaram acúmulo nos teores de açúcares e ácidos orgânicos, com predominância do ácido málico, o que levou ao abaixamento do $\mathrm{pH}$, comportamento também observado no presente trabalho.

De acordo com Vilas Boas et al. (2004), os sólidos solúveis são usados como indicadores de maturidade e também determinam a qualidade da fruta, exercendo importante papel no sabor. $\mathrm{Na}$ Tabela 1, pode-se observar que o teor de sólidos solúveis apresentou acréscimo para todas as cultivares, à medida que o estádio de maturação avançou de E2 (4,00 ${ }^{\circ}$ Brix) para E7 (21,41 ${ }^{\circ}$ Brix). De acordo com Bleinroth (1995), o valor máximo de sólidos solúveis alcançado para as diversas cultivares de bananeira é $27^{\circ}$ Brix, podendo diminuir quando a fruta se encontra madura. Observou-se também que, para o primeiro estádio analisado, não houve diferença estatística entre as três cultivares, porém, com o decorrer da maturação, verificaram-se diferenças significativas entre as cultivares estudadas, sendo que a cultivar Tropical apresentou, em todos os estádios avaliados, tendência de teores mais elevados de sólidos solúveis, com o máximo valor observado no estádio 7 , de $23,67^{\circ}$ Brix, significativamente superior ao observado para as demais cultivares estudadas. Jesus et al. (2004), estudando diferentes genótipos de bananeira, observaram teores de sólidos solúveis variando de 19,8 a $27,4^{\circ}$ Brix no fruto maduro, valores concordantes com o presente trabalho.

Vilas Boas et al. (2001) e Almeida et al. (2006) relatam que uma das modificações durante o amadurecimento de bananas é a hidrólise do amido, a qual culmina com o acúmulo de açúcares da polpa. Observa-se, na Tabela 1, que, para todas as cultivares analisadas, houve aumento significativo no teor de açúcares totais, redutores e não redutores no decorrer da maturação dos frutos. Ainda no que se refere aos açúcares, pode-se verificar, de maneira geral, diferenças significativas entre as cultivares estudadas, à exceção do estádio 2 , onde não houve diferenças significativas entre as cultivares analisadas, com valor médio de $1,39 \%$ para açúcares totais, $0,79 \%$ para açúcares redutores e $0,57 \%$ para açúcares não redutores. Entretanto, já a partir do estádio 3 de maturação, a cultivar Tropical começou a se destacar nos teores dos açúcares analisados, apresentando, no estádio ótimo para o consumo (E7), o maior teor de açúcares totais $(19,81 \%)$, seguida pela cv. Thap Maeo (17,02\%) e finalmente a cv. Caipira (16,84\%). $\mathrm{O}$ valor encontrado para cv. Tropical está próximo do obtido por Pinheiro et al. (2005), que observaram, para banana 'Maçã' in natura, 19,22\% de açúcares totais. De acordo com Álvares (2003), os açúcares representam, normalmente, de 0,5 a $2 \%$ da polpa de bananas verdes e aumentam de 15 a $20 \%$ quando a polpa amadurece, em razão da degradação do amido, fato observado também nos frutos das cultivares avaliadas neste estudo.

Os resultados obtidos na análise sensorial para as cultivares estudadas encontram-se na Tabela 2 , onde se verificou que as cultivares Tropical e Thap Maeo não apresentaram diferenças significativas entre si, observando-se, para as mesmas, as maiores notas médias com relação aos atributos aroma, cor, textura e sabor dos frutos. Já a cultivar Caipira recebeu as menores médias de aceitação para todos os atributos avaliados, entre 6,25 e 7,07, valores que correspondem, em uma escala estruturada de 9 pontos, a "gostei ligeiramente" e "gostei muito". Entretanto, mesmo 
apresentando as menores médias observadas, não se pode discriminar o plantio da cultivar Caipira na região em estudo, visto que, em função das notas obtidas, não se caracteriza a rejeição sensorial de nenhuma das três cultivares estudadas. Pelo contrário, de acordo com os resultados do teste de aceitação, confirma-se o potencial para cultivo e comerciali- zação das cultivares estudadas, na região de Belém (PA). Matsuura et al. (2002) também obtiveram boa aceitação sensorial avaliando a banana cv. Pacovan e dois híbridos desta cultivar, os quais apresentaram, para os mesmos atributos aqui avaliados, notas entre 6,0 e 7,0 .

TABELA 1 - Caracterização físico-química de cultivares de bananeira do grupo 'Maçã' em quatro estádios de maturação (E2, E3, E5 e E7), armazenadas sob condições ambiente $\left(28 \pm 3^{\circ} \mathrm{C}\right.$ e $74,5 \pm 16,5 \%$ UR). Belém-PA, 2009.

\begin{tabular}{|c|c|c|c|c|c|c|c|c|c|c|c|}
\hline Variável & Cultivar & & & Está & lios d & matur & ação & & & & \\
\hline & & E2 & & E3 & & E5 & & E7 & & Média & \\
\hline Firmeza $(\mathrm{N})$ & Caipira & 39,98 & $\mathrm{Ba}$ & 17,90 & $\mathrm{Ab}$ & 6,75 & $\mathrm{Bc}$ & 4,76 & Ac & 17,35 & B \\
\hline & Thap Maeo & 38,27 & $\mathrm{Ba}$ & 15,87 & $\mathrm{Ab}$ & 11,21 & Ac & 6,18 & Ad & 17,88 & B \\
\hline & Tropical & 52,02 & $\mathrm{Aa}$ & 16,90 & $\mathrm{Ab}$ & 6,06 & $\mathrm{Bc}$ & 5,22 & Ac & 20,05 & A \\
\hline & Média & 43,42 & $\mathrm{a}$ & 16,89 & $\mathrm{~b}$ & 8,01 & $\mathrm{c}$ & 5,39 & $\mathrm{~d}$ & 18,43 & \\
\hline$\overline{\mathrm{pH}}$ & Caipira & 5,34 & $\mathrm{Aa}$ & 4,78 & $\mathrm{Aa}$ & 4,67 & $\mathrm{Aa}$ & 4,93 & $\mathrm{Aa}$ & 4,93 & A \\
\hline & Thap Maeo & 5,44 & $\mathrm{Aa}$ & 4,31 & $\mathrm{Bb}$ & 4,33 & $\mathrm{Bb}$ & 4,18 & $\mathrm{Cc}$ & 4,57 & $\mathrm{C}$ \\
\hline & Tropical & 5,53 & $\mathrm{Aa}$ & 4,37 & $\mathrm{Bb}$ & 4,41 & $\mathrm{Bb}$ & 4,54 & $\mathrm{Bb}$ & 4,71 & $\mathrm{~B}$ \\
\hline & Média & 5,44 & $\mathrm{a}$ & 4,49 & $\mathrm{~b}$ & 4,47 & $\mathrm{~b}$ & 4,55 & $\mathrm{~b}$ & 4,74 & \\
\hline AT (\% ácido málico) & Caipira & 0,11 & $\mathrm{Bb}$ & 0,27 & $\mathrm{Ba}$ & 0,24 & $\mathrm{Ca}$ & 0,26 & $\mathrm{Ca}$ & 0,22 & $\mathrm{C}$ \\
\hline & Thap Maeo & 0,19 & Ac & 0,40 & $\mathrm{Ab}$ & 0,48 & $\mathrm{Aa}$ & 0,41 & $\mathrm{Ab}$ & 0,37 & A \\
\hline & Tropical & 0,10 & $\mathrm{Bc}$ & 0,28 & $\mathrm{Bb}$ & 0,34 & $\mathrm{Ba}$ & 0,32 & $\mathrm{Ba}$ & 0,26 & $\mathrm{~B}$ \\
\hline & Média & 0,13 & $\mathrm{c}$ & 0,32 & $\mathrm{~b}$ & 0,35 & $\mathrm{a}$ & 0,33 & $\mathrm{ab}$ & 0,28 & \\
\hline SS ( ${ }^{\circ}$ Brix $)$ & Caipira & 4,00 & Ad & 8,20 & $\mathrm{Cc}$ & 20,09 & $\mathrm{Ab}$ & 20,58 & $\mathrm{Ba}$ & 13,22 & $\mathrm{~B}$ \\
\hline & Thap Maeo & 4,00 & Ad & 10,00 & $\mathrm{Bc}$ & 13,07 & $\mathrm{Bb}$ & 20,00 & $\mathrm{Ba}$ & 11,77 & $\mathrm{C}$ \\
\hline & Tropical & 4,00 & Ad & 16,00 & Ac & 20,27 & $\mathrm{Ab}$ & 23,67 & $\mathrm{Aa}$ & 15,98 & A \\
\hline & Média & 4,00 & $\mathrm{~d}$ & 11,40 & $\mathrm{c}$ & 17,81 & $\mathrm{~b}$ & 21,41 & $\mathrm{a}$ & 13,66 & \\
\hline Açúcares totais (\%) & Caipira & 1,11 & Ad & 4,58 & $\mathrm{Cc}$ & 11,99 & $\mathrm{Bb}$ & 16,84 & $\mathrm{Ba}$ & 8,63 & $\mathrm{C}$ \\
\hline & Thap Maeo & 1,61 & Ad & 8,34 & $\mathrm{Bc}$ & 11,32 & $\mathrm{Bb}$ & 17,02 & $\mathrm{Ba}$ & 9,57 & B \\
\hline & Tropical & 1,46 & Ad & 12,19 & Ac & 14,94 & $\mathrm{Ab}$ & 19,81 & $\mathrm{Aa}$ & 12,10 & A \\
\hline & Média & 1,39 & $\mathrm{~d}$ & 8,37 & $\mathrm{c}$ & 12,75 & $\mathrm{~b}$ & 17,89 & $\mathrm{a}$ & 10,10 & \\
\hline Açúcares redutores & Caipira & 0,75 & $\mathrm{Ad}$ & 2,72 & $\mathrm{Cc}$ & 9,73 & $\mathrm{Bb}$ & 11,20 & $\mathrm{Ba}$ & 6,10 & $\mathrm{C}$ \\
\hline & Thap Maeo & 0,71 & Ad & 6,01 & $\mathrm{Bc}$ & 9,77 & $\mathrm{Bb}$ & 15,55 & $\mathrm{Aa}$ & 8,01 & B \\
\hline & Tropical & 0,91 & Ad & 10,51 & Ac & 13,04 & $\mathrm{Ab}$ & 14,86 & $\mathrm{Aa}$ & 9,83 & A \\
\hline & Média & 0,79 & $\mathrm{~d}$ & 6,41 & $\mathrm{c}$ & 10,85 & $\mathrm{~b}$ & 13,87 & $\mathrm{a}$ & 7,98 & \\
\hline Açúcares não reduto- & Caipira & 0,34 & Ac & 1,77 & $\mathrm{Ab}$ & 2,15 & $\mathrm{Ab}$ & 5,36 & $\mathrm{Aa}$ & 2,40 & A \\
\hline & Thap Maeo & 0,85 & $\mathrm{Ab}$ & 2,21 & $\mathrm{Aa}$ & 1,47 & $\mathrm{Aab}$ & 1,40 & $\mathrm{Bab}$ & 1,48 & B \\
\hline & Tropical & 0,53 & Ac & 1,60 & $\mathrm{Ab}$ & 1,80 & $\mathrm{Ab}$ & 4,70 & $\mathrm{Aa}$ & 2,16 & A \\
\hline & Média & 0,57 & $\mathrm{c}$ & 1,86 & $\mathrm{~b}$ & 1,80 & $\mathrm{~b}$ & 3,82 & $\mathrm{a}$ & 2,01 & \\
\hline
\end{tabular}

Médias seguidas de mesmas letras, maiúsculas (efeito das cultivares) nas colunas e minúsculas (efeito dos estádios de maturação) nas linhas, não diferem entre si, pelo Teste de Tukey, a $5 \%$ de probabilidade. 


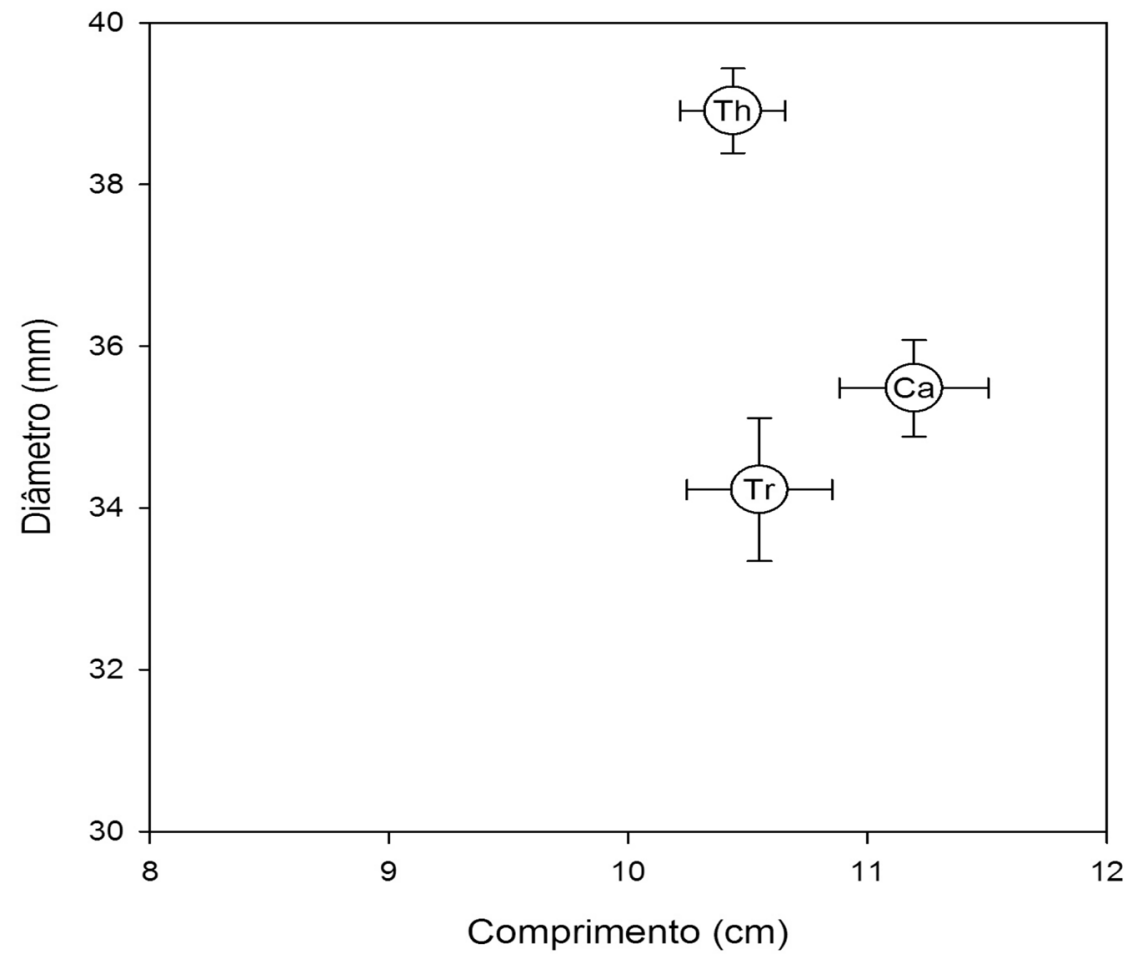

FIGURA 1 - Valores médios de comprimento e diâmetro dos frutos de bananeiras Caipira (Ca), Thap Maeo (Th) e Tropical (Tr).

TABELA 2 - Médias das notas obtidas para o teste de aceitação de cultivares de banana do grupo Maçã.

\begin{tabular}{ccccc}
\hline Cultivar & Aroma & Cor & Textura & Sabor \\
\hline Caipira & $6,33 \pm 1,87 \mathrm{~b}$ & $7,07 \pm 1,35 \mathrm{~b}$ & $7,00 \pm 1,44 \mathrm{~b}$ & $6,25 \pm 2,18 \mathrm{~b}$ \\
Thap Maeo & $7,60 \pm 1,12 \mathrm{a}$ & $7,73 \pm 1,09 \mathrm{a}$ & $7,82 \pm 1,14 \mathrm{a}$ & $7,50 \pm 1,27 \mathrm{a}$ \\
Tropical & $7,08 \pm 1,99 \mathrm{a}$ & $7,40 \pm 1,45 \mathrm{ab}$ & $7,38 \pm 1,50 \mathrm{ab}$ & $7,28 \pm 1,54 \mathrm{a}$ \\
\hline
\end{tabular}

Valores são médias \pm desvio-padrão.

Médias seguidas de mesma letra, na coluna, não diferem entre si, pelo teste de Tukey, a 5\% de probabilidade.

\section{CONCLUSÃO}

1-Os frutos de bananeira das cultivares Tropical, Thap Maeo e Caipira apresentam características físico-químicas semelhantes às bananas pertencentes ao subgrupo Maçã.

2-Durante a maturação dos frutos, observa redução da firmeza da polpa e do $\mathrm{pH}$, e aumento da acidez titulável, açúcares totais, redutores e não redutores para as três cultivares avaliadas.

3-Os frutos dessas três cultivares mostram boa aceitabilidade sensorial, com destaque para a Thap Maeo e a Tropical, indicando potencial para serem cultivadas e comercializadas na região em estudo.

\section{REFERÊNCIAS}

AGUiAR, L. M. A. Avaliação do processo de concentração osmótica para obtenção de bananapassa. 2006. 103 f. Dissertação (Mestrado em Tecnologia de Alimentos) - Faculdade de Engenharia de Alimentos, Universidade Estadual de Campinas, Campinas, 2006.

ALENCAR, F. M. A.; SILVA, M. M.; LIMA, M. A. C.; SILVA, G. G. B.; CASTRO, F. Evolução da maturação e determinação do ponto de colheita de banana nas condições de cultivo da região do submédio do vale do São Francisco. 2010. Disponível em: <http://www.infoteca.cnptia.embrapa.br/ bitstream/CPATSA/34351/1/OPB1015.pdf $>$. Acesso em: 25 jan. 2011. 
ALMEIDA, G. C.; VILAS BOAS, E. V. de B.; RODRIGUES, L. J.; DE PAULA, N. R. Atraso do amadurecimento de banana 'maçã' pelo 1-MCP, aplicado previamente à refrigeração. Revista Brasileira de Fruticultura, Jaboticabal, v. 28, n. 2, p. 319-321, 2006.

ÁlVARES, V. S. Amadurecimento e qualidade da banana "Prata" (Musa AAB subgrupo Prata) submetida a diferentes concentrações de etileno. 2003. 70f. Dissertação (Mestrado em Produção Vegetal) - Universidade Federal de Viçosa, Viçosa, 2003.

AOAC. Official methods of analysis of the Association of Official Analytical Chemists. 16. ed. Washington, 1997.

BLEINROTH, E. W. Matéria-prima. In: MEDINA, J. C.; BLEINROTH, E. W.; MARTIN, Z. J. de.; MORETTI, V. A. Banana: cultura, matéria-prima, processamento e aspectos econômicos. 2. ed. Campinas: Instituto de Tecnologia de Alimentos, 1995. p.133-196.

CEAGESP. Ficha da banana. Disponível em: $<$ http://www.ceagesp.gov.br/hortiescolha/anexos/ ficha_banana.pdf $>$. Acesso em: 06 jul. 2010.

IBRAF. Instituto Brasileiro de Frutas. Produção brasileira de frutas 2007. Disponível em: <http:// www.ibraf.org.br/estatisticas/ProducaoBrasileiradeFrutas2007.pdf>. Acesso em: 05 jul. 2010.

Chitarra, M. I. F.; Chitarra, A. B. Pós-colheita de frutos e hortaliças: fisiologia e manuseio. 2. ed. Lavras: UFLA, 2005. 783p.

JESUS, S. C.; FOLEGATTI, M. I. S.; MATSUURA, F. C.A. U.; CARDOSO, R. L. Caracterização física e química de frutos de diferentes genótipos de bananeira. Bragantia, Campinas, v.63, n.3, p.315-323, 2004.

LEONEL, S.; DAMATTO JUNIOR, E. R. Caracterização das áreas de cultivo da bananeira 'maçã' na região de Ribeirão do Sul-SP. Ciência e Agrotecnologia, Lavras, v.31, n.4, p.958-965, 2007.

LUCENA, E. M. P. L.; JÚNIOR, A. S.; SILVA, A. M. C.; CAMPELO, I. K. M.; SOUSA, J. S.; COSTA, T. L.; MARQUES, L. F.; PAIXÃO, F. J. R. Uso de etileno exógeno na maturação da banana variedade prata-anã. Revista Brasileira de Produtos Agroindustriais, Campina Grande, v.6, n.1, p.55-60, 2004.
MATSUURA, F. C. A. U.; CARDOSO, R. L.; RIBEIRO, D. E. Qualidade sensorial de frutos de híbridos de bananeira cultivar Pacovan. Revista Brasileira de Fruticultura, Jaboticabal, v.24, n.1, p.263-266, 2002.

MATSUURA, F. C. A. U.; COSTA, J. I. P.; FOLEGATTI, M. I. S. Marketing de banana: preferências do consumidor quanto aos atributos de qualidade dos frutos. Revista Brasileira de Fruticultura, Jaboticabal, v.26, n.1, p.48-52, 2004.

MATSUURA, F. C. A. U.; SILVEIRA, M. I. da. Banana: Pós-Colheita. Brasília: Embrapa Comunicação para Transferência de Tecnologia, 2001. 71p. (Frutas do Brasil, 16).

MATTOS, L. A.; SILVA, S. O.; AMORIM, E. P.; AMORIM, T. B. Caracterização físico-química de cultivares de bananeira. Disponível em: $<\mathrm{http} / /$ www.cnpmf.embrapa.br/publicacoes/jornada/resumos/Resumo_LorenaAM_SebastiaoOS_rev_JR_ ED__.pdf $>$. Acesso em: 09 jul. 2010.

MEDINA, M. V.; PEREIRA, M. E. C. Banana. Disponível em: $<$ http://www.agencia.cnptia.embrapa.br/ recursos/Livro_Banana_Cap_12ID-ZU0HVGp1W7. pdf $>$. Acesso em: 10 jul. 2010.

PBMH \& PIF - PROGRAMA BRASILEIRO PARA A MODERNIZAÇÃO DA HORTICULTURA \& PRODUÇÃO INTEGRADA DE FRUTAS. Normas de classificação de banana. São Paulo: CEAGESP, 2006. (Documentos, 29).

PEREIRA, V. L.; ALVARENGA, Â. A.; MATOS, L. E. S.; SILVA, C. R. R. Avaliação de cultivares de bananeira (Musa spp., AAB) em três locais do Estado de Minas Gerais. Ciência e Agrotecnologia, Lavras, p.1.373-1.382, 2002. Edição Especial,

PINHEIRO, A. C. M.; VILAS BOAS, E. V. B.; MESQUITA, C. T. Ação do 1-metilciclopropano (1MCP) na vida de prateleira da banana-maçã. Revista Brasileira de Fruticultura, Jaboticabal, v.27, n.1, p.25-28, 2005.

SILVA, E. A.; BOLIANI, A. C.; CORRÊA, L. S. Avaliação de cultivares de bananeira (Musa sp) na região de Selvíria-MT. Revista Brasileira de Fruticultura, Jaboticabal, v.28, n.1, p.101-103, 2006. 
SILVA, S. O.; FLORES, J. C.; LIMA NETO, F. P. Avaliação de cultivares e híbridos de bananeira em quatro ciclos de produção. Pesquisa Agropecuária Brasileira, Brasília, v.37, n.11, p.1.567-1.574, 2002.

STONE, H. S.; SIDEL, J. L. Sensory evaluation practies. 2. ed. San Diego: Academic Press, 1993. $338 \mathrm{p}$.

VILAS BOAS, B. M.; NUNES, E. E.; FIORINI, F. V. A.; LIMA, L. C. de O.; VILAS BOAS, E. V. de B.; COELHO, A. H. R. Avaliação da qualidade de mangas 'Tommy Atkins' minimamente processadas. Revista Brasileira de Fruticultura, Jaboticabal, v.26, n.3, p.540-543, 2004.
VILAS BOAS, E. V. B.; ALVES, R. E.; FILGUEIRAS, H. A. C.; MENEZES, J. B. Características da fruta: banana pós-colheita. Brasília: EMBRAPA, 2001. p.15-19. (Série Frutas do Brasil, 16).

VILAS BOAS, E. V. B.; RODRIGUES, L. J.; DE PAULA, N. R. F. Modificações físicas, físico-químicas e químicas da banana 'maçã' durante o amadurecimento. In: SIMPÓSIO LATINO-AMERICANO DE CIÊNCIA E TECNOLOGIA DE ALIMENTOS, 5., 2003, Campinas. Anais... Campinas: Unicamp, 2003. CD-ROM. 